\title{
DEBATE
}

\section{QUE É GUETO? CONSTRUINDO UM CONCEITO SOCIOLÓGICO}

\author{
Loïc Wacquant
}

\begin{abstract}
RESUMO
Ao invés de produzirem um conceito analiticamente robusto de "gueto", as Ciências Sociais utilizam o termo de maneira descritiva, não raro thes conferindo significados do senso comum emprestados das sociedades em que o fenômeno é identificado. A partir da produção historiográfica sobre a diáspora judaica na Europa renascentista, da Sociologia da experiência negra na metrópole fordista dos EUA e da Antropologia da marginalidade étnica na Ásia Oriental, este artigo constrói um conceito relacional de gueto como um instrumento bifacetado [Janus faced] de cercamento e controle etno-racial. Por meio desse procedimento, o gueto revela-se como um dispositivo sócio-organizador composto de quatro elementos (estigma, limite, confinamento espacial e encapsulamento institucional) que emprega o espaço para reconciliar seus dois propósitos contraditórios: exploração econômica e ostracismo social. O gueto não é uma "área natural", produto da "história da migração" (como Louis Wirth defendia), mas sim uma forma especial de violência coletiva concretizada no espaço urbano. A articulação do conceito de gueto possibilita o desvelamento da relação entre "guetização", pobreza urbana e segregação, assim como o esclarecimento das diferenças estruturais e funcionais entre guetos e aglomerações étnicas. Esse proceder também possibilita que realcemos o papel do gueto como matriz e incubador simbólico da produção de uma identidade maculada, indicando que seu estudo seja feito por analogia a outras instituições voltadas para o confinamento forçado de grupos despossuidos e desonrados como o campo de refugiados, a reserva e a prisão.
\end{abstract}

PALAVRAS-CHAVE: gueto; conceituação; cercamento etno-racial; controle social.

\section{INTRODUÇÃO}

Enquanto as Ciências Sociais fazem uso corrente do termo "gueto" de maneira descritiva, elas paradoxalmente não produziram uma definição analítica para o mesmo. Tanto na historiografia da diáspora judaica do começo da era moderna e durante o nazismo, como na Sociologia da experiência negra na metrópole do século XX e na Antropologia sobre a marginalidade étnica na África e na Ásia Oriental, ou seja, nas três áreas em que o termo é empregado, o "gueto" denota uma área urbana restrita, uma rede de instituições ligadas a grupos específicos e uma constelação cultural e cognitiva (valores, formas de pensar ou mentalidades) que implica tanto o isolamento sócio-moral de uma categoria estigmatizada quanto o truncamento sistemático do espaço e das oportunidades de vida de seus integrantes. Mas ne-

\footnotetext{
1 Este artigo será publicado em Smelser e Baltes (2004). Tradução de Zena Eisenberg e João Feres Júnior.
}

nhuma dessas linhas de pesquisa tomou para si o ônus de especificar o que faz do gueto uma forma social, ou quais de suas características são constitutivas e quais são derivativas; pelo contrário, as diferentes pesquisas têm, em suas épocas respectivas, adotado a definição do senso comum que prevalece na sociedade examinada - o que explica o fato de o conceito, que parece óbvio, não aparecer em grande parte dos dicionários de Ciências Sociais, nem mesmo nas edições anteriores desta enciclopédia.

\section{UM CONCEITO OPACO E MUTANTE}

Dessa maneira, o campo semântico do conceito "gueto" na sociedade e nas Ciências Sociais norte-americanas, cujo domínio da investigação sobre esse tópico tem sido tanto quantitativo quanto temático, tem sucessivamente se expandido e se contraído, acompanhando assim a maneira como elites políticas e intelectuais conceituam o nexo perverso entre etnia e pobreza no meio urbano (WARD, 1989). Inicialmente, na última metade do século XIX, o termo era usado para referir-se a concentrações residenciais de judeus eu- 
ropeus nos portos do Atlântico e era claramente distinto de slum $^{2}$ enquanto área de moradia precária e de patologia social. O conceito expandiuse durante a Progressive Era e passou a incluir todos os distritos urbanos degradados ${ }^{3}$ onde imigrantes exóticos juntavam-se - mais especificamente, imigrantes pobres do Sudeste europeu e afro-americanos fugindo do regime Jim Crow de submissão de castas no Sul dos EUA. Na medida em que o termo refletia preocupações da classe dominante com relação à assimilação desses grupos ao padrão anglo-saxão predominante no país, o "gueto" referia-se, nesse contexto, à intersecção entre bairros étnicos e slums, em que a segregação juntava-se ao abandono físico e à superpopulação, exacerbando assim males urbanos como a criminalidade, a desintegração familiar, a pobreza e a falta de participação na vida nacional. $\mathrm{O}$ conceito recebeu autoridade científica com o paradigma ecológico da Escola de Sociologia de Chicago. Em seu livro clássico, The Ghetto, Louis Wirth (1928, p. 6) junta ao gueto judeu da Europa medieval outros guetos: Pequenas Sicílias, Pequenas Polônias ${ }^{4}$, Chinatowns e cinturões negros das cidades grandes, assim como "áreas do vício", pululando com tipos marginais tais como vagabundos, boêmios e prostitutas - todas eles consideradas áreas criadas "naturalmente" a partir de um desejo universal de diferentes grupos de "preservar seus hábitos culturais peculiares", e cada uma cumprindo sua "função" específica no grande organismo urbano.

O conceito foi modificado depois da II Guerra, sob a pressão do movimento dos direitos civis

\footnotetext{
2 Um slum é uma área de dilapidação imobiliária que, por extensão, tende a designar uma vizinhança de má reputação e indesejável para as classes baixas. Essa palavra descreve um tipo de ocupação urbana similar à das favelas brasileiras, mas que também pode ser aplicada para descrever algo similar aos cortiços (nota dos tradutores).

3 O termo no original é "inner city", uma expressão que nomeia os indesejados bairros centrais das cidades norteamericanas, ocupados primeiramente pelas indústrias e depois pelas populações de classes baixas e que, a partir da década de 1950, começaram a ser abandonados pela brancos ("white flight"), o que acarretou uma desvalorização imobiliária drástica, e conseqüente deterioração do tecido urbano (N. T.).

4 No original, "Little Sicilies, Little Polands": uma referência aos nomes que alguns bairros étnicos receberam nos Estados Unidos, em relação às regiões ou aos países de onde vieram essas etnias (N. T.).
}

e passou a referir-se aos enclaves compactos e saturados a que os afro-americanos eram relegados quando migravam para os centros industriais do Norte dos EUA. Havia então um forte contraste entre o crescimento de uma "metrópole negra no seio de outra branca", onde os negros desenvolviam instituições distintas e paralelas para compensar e proteger-se do isolamento imposto pelos brancos (DRAKE \& CAYTON, 1945), e a dispersão residencial dos euro-americanos de descendência estrangeira. Durante o ápice das revoltas negras dos anos 1960, Kenneth Clark (1965, p. 11) escreveu sobre a relação de subordinação etnoracial e fez dela o epicentro de sua análise do Gueto escuro e seus infortúnios: "Os EUA adicionaram ao conceito de gueto a restrição das pessoas a uma área específica e a limitação de sua liberdade de escolha com base na sua cor. As paredes invisíveis do gueto escuro foram erigidas pela sociedade branca, por aqueles que têm o poder". Esse diagnóstico foi confirmado pela Comissão Kerner (1989 [1968], p. 2), uma força-tarefa supra-partidária indicada pelo Presidente Johnson, cujo relatório oficial sobre a "desordem civil" que abalou a metrópole norte-americana ganhou fama por culpar a intransigência racial dos brancos pelo fato de os EUA estarem "transformando-se em duas sociedades, uma negra e outra branca - segregadas e desiguais". Contudo, nas duas décadas seguintes, o gueto escuro entrou em decadência devido à desindustrialização e às políticas estaduais de redução da previdência e compactação urbana, tornando-se um território abandonado, foco de terror e desintegração. Além disso, na medida em que a dominação racial tornava-se cada vez mais difusa e difratada através do prisma de classe, o conceito foi substituído por uma díade maneirada pelo eufemismo geográfico "centro urbano" e pelo neologismo "underclass" se a um substrato de residentes do gueto associados a comportamentos anti-sociais, altas taxas de desemprego e isolamento social (WILSON, 1987). Nos anos 1990, a neutralização do termo "gueto" na pesquisa orientada ao planejamento de políticas públicas culminou com o expurgo de qualquer traço de raça ou poder, redefinindo assim o termo como qualquer grupo de pobreza extrema, independente de sua composição populacional ou institucional. Dessa forma, o conceito de gueto

\footnotetext{
5 Para uma exegese sociológica dessa noção, cf. Wacquant (1997) (N. T.).
} 
regrediu à sua condição anterior de slum.

O significado do termo foi ainda mais dissolvido ao ser aplicado ao estudo dos padrões sócioculturais específicos dos homossexuais em cidades de sociedades avançadas "em resposta ao estigma e à libertação gay", depois das revoltas de Stonewall (LEVINE, 1979, p. 31); na Europa Ocidental, o conceito foi dissolvido por meio de animados debates científicos e políticos sobre as ligações entre a imigração pós-colonial, reestruturação econômica pós-industrial e a dualização urbana (MINGIONE, 1996). Mesmo assim, pode-se extrair dessas diferentes literaturas algumas semelhanças e propriedades recorrentes na construção de um conceito relacional de gueto como um instrumento de cercamento $e$ controle, o que esclarece grande parte da confusão que o circunda e faz dele um instrumento poderoso de análise social da dominação etno-racial e da desigualdade urbana. Para isso, basta que retornemos às origens históricas da palavra e do fenômeno que o termo descrevia, na Veneza da Renascença.

\section{UMA INSTITUIÇÃO BIFACETADA DE CERCAMENTO E CONTROLE ÉTNICO}

Cunhado por derivação do italiano giudecca, borghetto ou gietto (ou do alemão gitter ou do hebreu talmúdico get, de etimologia controversa), a palavra "gueto" inicialmente se referia à consignação forçada de judeus a distritos especiais por parte de autoridades políticas e religiosas da cidade. Na Europa medieval, os judeus comumente se agrupavam em uma área urbana, onde administravam seus negócios e seguiam seus costumes. Essas áreas eram doadas ou vendidas como um privilégio para atraí-los para as cidades e principados onde ocupavam cargos importantes de credores, fiscais e comerciantes. No entanto, entre os séculos XIII e XVI, no início dos motins causados pelas Cruzadas, os favores aos poucos tornaram-se obrigações (STOW, 1982). Em 1516, o Senado de Veneza ordenou que todos os judeus fossem relocados para o ghetto nuovo, uma fundição abandonada em uma ilha isolada, cercada por dois muros altos cujas janelas exteriores e portas eram vedadas. Vigias guardavam suas duas pontes e patrulhavam de barco os canais adjacentes. Os judeus eram autorizados a sair durante o dia para suas ocupações, mas tinham que vestir um traje distintivo e retornar para dentro dos portões antes do pôr do sol, sob pena de um cas- tigo grave caso não o fizessem. Essas medidas eram desenhadas como alternativa à expulsão, pois assim a cidade-Estado beneficiava-se economicamente da presença dos judeus (incluindo aluguel, impostos e coletas forçadas) enquanto protegia seus residentes cristãos da contaminação por corpos concebidos como sujos e sensualmente perigosos, que carregavam sífilis e eram vetores de heresia, além de portar a mácula da usura e do dinheiro, algo que a Igreja Católica igualava à prostituição (SENNETT, 1994, p. 224).

Esse modelo veneziano disseminou-se pelas cidades da Europa e pelas margens do Mediterrâneo (JOHNSON, 1997, p. 235-245). Se por um lado a fixação e a exclusão territorial acarretados por esse processo trouxeram a superpopulação, a deterioração das condições de moradia, o empobrecimento e altas taxas de morbidade e mortalidade, por outro levaram também ao florescimento institucional e à consolidação cultural. À medida que os judeus respondiam a restrições cívicas e ocupacionais cada vez maiores, criavam uma teia extensa de organizações que serviam como instrumentos de ajuda coletiva e de solidariedade: mercados, associações empresariais, grupos de caridade e de ajuda e locais de adoração e de estudos religiosos. O Judenstadt de Praga, o maior gueto da Europa do século XVIII, tinha até sua própria prefeitura, o Rathaus, que era emblema da autonomia relativa e força comunitária de seus residentes. Às suas sinagogas confiava-se não só a liderança espiritual, como também a supervisão administrativa e judicial da população. A vida social do gueto judeu era voltada para dentro, quase que "superorganizada" (WIRTH, 1928. p. 62), de maneira que reforçava tanto a integração interna como a exclusão do externo.

Podem ser detectados nesse momento inaugural os quatro elementos que constituem o gueto, isto é, o estigma, o limite, o confinamento espacial e o encapsulamento institucional. O gueto é um meio sócio-organizacional que usa o espaço com o fim de conciliar dois objetivos antinômicos: maximizar os lucros materiais extraídos de um grupo visto como pervertido e perversor e minimizar o contato íntimo com seus membros, a fim de evitar a ameaça de corrosão simbólica e de contágio. Esse mesmo raciocínio duplo de exploração econômica cum ostracismo social dominou a gênese, a estrutura e o funcionamento do gueto afro-americano na metrópole fordista durante a 
maior parte do século XX. Negros eram recrutados nas cidades norte-americanas depois da I Guerra Mundial pelo seu trabalho não qualificado, que era indispensável nas indústrias que formavam o centro da crescente economia industrial. Ao mesmo tempo, não havia perigo de eles misturarem-se ou confraternizarem com os brancos, que os consideravam vis, naturalmente inferiores e com orgulho étnico maculado pela escravidão. À medida que os negros migravam do Sul aos milhões, a hostilidade branca aumentava e os padrões de discriminação e segregação, que até então eram inconsistentes e limitavam-se à esfera informal, não só se tornaram mais rígidos na moradia, escola e nas acomodações públicas, como também se estenderam à economia e à política (SPEAR, 1968; OSOFSKY, 1971). Os afro-americanos então não tiveram escolha, a não ser fugir para dentro do perímetro do Cinturão Negro [Black Belt] e tentar desenvolver uma rede de instituições próprias que cuidassem das necessidades básicas da comunidade refugiada. Surgiu assim uma cidade paralela fundamentada em igrejas e jornais para negros, clubes negros, pensões para negros, escolas e empresas para negros e associações políticas e civis negras. Essa cidade paralela ficava no centro da metrópole branca, ainda que isolada por uma cerca construída por costumes, dissuasão legal, discriminação econômica (por bancos, corretores e pelo Estado) e, também, da violência manifesta dos açoites, bombas incendiárias e motins que intimidavam aqueles que ousassem atravessar a linha racial.

Esse paralelismo institucional imposto, que se predicava no isolamento espacial inflexível - e não na pobreza extrema, condições subumanas de moradia, diferença cultural ou no simples isolamento residencial -, é o que tem diferenciado os afro-americanos de outros grupos na história dos EUA, como já sugeriram importantes estudiosos da experiência urbana negra, de W. E. B. Du Bois e E. Franklin Frazier a Drake e Cayton, Kenneth Clark e Oliver Cox (WACQUANT, 1998). Esse fenômeno também pode ser observado na trajetória dos burakumins na cidade japonesa após o fim da era Tokugawa (HANE, 1982). Na condição de descendentes do eta, a casta mais baixa das quatro que compõem o sistema feudal japonês, os burakumins eram intocáveis aos olhos das religiões budista e xintoísta e ficavam confinados por lei, desde o pôr do sol até o levantar, a pequenos vilarejos (buraku). Lá eram obrigados a vestir uma coleira amarela e a andar descalços, a ficar de quatro quando falassem com pessoas de outras castas e a casar somente com pessoas da mesma casta. Apesar de oficialmente emancipados em 1871, ao migrarem para cidades foram forçados a restringir-se a bairros próximos aos depósitos de lixo, crematórios, prisões e açougues, lugares vistos como ninhos de criminalidade e imoralidade. Excluídos de empregos na indústria, sobravalhes apenas os empregos mal pagos e de baixo prestígio. Os burakumins eram mandados para escolas separadas e compelidos à endogamia devido à pecha perene em seu sangue, prática feita possível por meio dos "registros de família" (DEVOS \& WAGATSUMA, 1966). No fim dos anos 1970, de acordo com a Liga de Defesa dos Burakumins [Burakumin Defense League], estimava-se que eles já eram 3 milhões, todos confinados em 6000 guetos espalhados por aproximadamente 1000 cidades da ilha.

Espalhados por três continentes e cinco países, casos como os dos judeus, afro-americanos e burakumins demonstram que o gueto não é, $a$ despeito de Wirth (1928, p. 284-285), uma "área natural" que surge pela adaptação ambiental governada por uma lógica biótica "parecida com a cooperação competitiva em que se baseia a comunidade vegetal". O erro da primeira Escola de Chicago consiste em "converter história em história natural" e considerar a "guetização" uma "manifestação da natureza humana" que seria parte da "história das migrações" (idem, p. 285), quando na verdade é uma forma muito peculiar de urbanização modificada por relações assimétricas de poder entre grupos etnoraciais: uma forma especial de violência coletiva concretizada no espaço urbano. Essa "guetização" não é um processo "descontrolado e sem concepção", como Robert E. Park defendeu em seu prefácio para $O$ gueto (idem, p. viii). Isso ficou claro a partir da II Guerra quando o gueto negro foi reconstruído de cima para baixo por meio de políticas públicas de habitação, renovação urbana e desenvolvimento econômico das periferias, ações que visavam remediar a separação rígida entre os negros e brancos (HIRSCH, 1983). A "guetização" é ainda mais aguda no contexto das "cidades de casta" construídas pelo poder colonial para demarcar o espaço da organização étnica hierárquica de suas posses transoceânicas, como Rabá sob o domínio francês no Marrocos ou a Cidade do Cabo depois da passagem do Group Areas Acts [Leis de Áreas de 
Grupos] durante o regime do apartheid na África do Sul (AUB-LUGHOD, 1980; WESTERN, 1982).

O reconhecimento de que o gueto é um produto e um instrumento de poder de um grupo permite-nos a apreciação de que na sua forma completa ele é uma instituição de duas faces, na medida em que serve a funções opostas para dois coletivos aos quais une em uma relação assimétrica de dependência. Para a categoria dominante, sua função é circunscrever e controlar, o que se traduz no que Max Weber chamou de "cercamento excludente" da categoria dominada. Para esta última, no entanto, trata-se de um recurso integrador e protetor na medida em que livra seus membros de um contato constante com os dominantes e permite colaboração e formação de uma comunidade dentro da esfera restrita de relações criada. $\mathrm{O}$ isolamento imposto pelo exterior leva a uma intensificação do intercâmbio social e cultural dentro do gueto. O gueto é o produto de uma dialética móvel e tensa entre a hostilidade externa e a afinidade interna que se expressa como uma ambivalência no nível do consciente coletivo. Por exemplo, mesmo que os judeus europeus protestassem contra sua relegação a distritos isolados, eles também tornaram-se profundamente ligados a esses lugares, apreciando a relativa segurança e as formas especiais de vida coletiva por eles proporcionadas. O gueto de Frankfurt do século XVIII não era "apenas um cenário de confinamento e perseguição, mas um lugar onde os judeus estavam completamente em casa" (GAY, 1992, p. 67). Assim também os negros tinham orgulho de ter "construído uma comunidade à sua própria imagem", mesmo ressentindo o fato de tê-lo feito sob coerção, resultado da intransigente exclusão branca, cujo objetivo era espantar o fantasma da "igualdade social" representado pela miscigenação (DRAKE \& CAYTON, 1945, p. 115).

\section{DISTINGUINDO POBREZA, SEGREGAÇÃO EAGLOMERAÇÃO ÉTNICA}

Articular o conceito de gueto permite-nos distinguir a relação entre "guetização", pobreza urbana e segregação e, assim, esclarecer as diferenças estruturais e funcionais entre os guetos e os bairros étnicos. Também nos permite salientar o papel do gueto como um incubador social e matriz na produção de uma identidade maculada.

1. A pobreza é uma característica freqüente, porém derivativa e variável, dos guetos: o fato de a maioria dos guetos historicamente terem sido lu- gares de miséria endêmica e não raro aguda, devido à carência de espaço, densidade demográfica e da exploração econômica e do maltrato generalizado de seus residentes, não implica que o gueto necessariamente seja um lugar de destituição ou um lugar uniformemente desprovido. O Judengasse de Frankfurt, instituído em 1490 e abolido em 1811, passou tanto por períodos de prosperidade como de penúria e continha áreas de opulência acentuada, na medida em que judeus da corte ajudavam a cidade a tornar-se um centro atrativo de troca e finanças - parte de seu encanto até hoje vem de ter sido o lar da dinastia dos Rothschild (WIRTH, 1928, cap. 4). James Weldon Johnson (1937, p. 4) afirmou que o Harlem nos anos 1930 não era um slum ou periferia, mas a "capital cultural" dos negros dos EUA, onde "as vantagens e oportunidades dos negros eram maiores do que em qualquer outro lugar do país". Da mesma forma o "Bronzeville" de Chicago era muito mais próspero em meados do século do que as comunidades negras do Sul e continha também a burguesia afro-americana mais afluente da época (DRAKE \& CAYTON, 1945). O fato de um gueto ser pobre depende de fatores externos como a demografia, ecologia, políticas públicas e o estado da economia que o circunda.

Por outro lado, nem todos os distritos despossuídos e dilapidados são necessariamente guetos. Por exemplo, os bairros brancos decadentes das cidades desindustrializadas do CentroOeste norte-americano, as Midlands na Inglaterra, os vilarejos rurais deprimidos na Alemanha Oriental e Sul da Itália e as villa miserias da grande Buenos Aires no fim do século XX são todos territórios de decadência e decomposição da classe trabalhadora, mas não cápsulas étnicas dedicadas a manter um grupo excluído numa relação de subordinação separatista. Independentemente de sua pobreza, eles não são guetos, a não ser no sentido metafórico. Se índices extremos de pobreza fossem suficientes para constituir um gueto, então grande parte da União Soviética e a maioria das cidades do Terceiro Mundo seriam guetos gargantuanos. As favelas das metrópoles brasileiras, que são freqüentemente retratadas como refúgios de abandono e desorganização, nada mais são do que bairros da classe trabalhadora com laços bem definidos tanto com a indústria como com os bairros afluentes, aos quais fornecem serviços caseiros. Assim também ocorre nos ranchos da Venezuela e nas poblaciones do Chile, 
onde as famílias que vivem nesses acampamentos irregulares variam muito de cor e têm laços genealógicos fortes com famílias de maior poder aquisitivo. Elas não são "social ou culturalmente marginalizadas, mas sim estigmatizadas e excluídas de um sistema de classes fechado" (PERLMAN 1976, p. 195; também QUIJANO, 1968). Dado que nem todos os guetos são pobres e que nem todas as áreas pobres são guetos, não se pode simplificar e confundir a análise da "guetização" com o estudo de slums e outros distritos de classe baixa da cidade.

\section{Assim, todos os guetos são segregados mas nem} todas as áreas segregadas são guetos. Os bairros seletos do Oeste de Paris, os subúrbios exclusivos da classe alta de Boston ou de Berlim, as "comunidades cercadas" que cresceram muito em cidades globais como São Paulo, Toronto e Miami, são todos iguais em termos de riqueza, renda, ocupação e em muitos casos etnia, mas nem por isso são guetos. A segregação neles é inteiramente voluntária e eletiva e por isso não são inclusivos ou perpétuos. Enclaves fortificados de luxo proporcionam "segurança, exclusão, homogeneidade social, amenidades e serviços", que permitem que famílias burguesas escapem do que consideram "o caos, sujeira e o perigo da cidade" (CALDEIRA 2000, p. 264-265). Essas ilhas de privilégio servem para aumentar, e não deprimir, as oportunidades de seus residentes, assim como para proteger seus modos de vida. Elas irradiam uma aura positiva de superioridade e não uma sensação de infâmia ou de pavor.

Isso sugere que a segregação residencial é uma condição necessária mas não suficiente para a "guetização". Para que um gueto surja, o confinamento espacial deve ser primeiramente imposto e abrangente e, em segundo lugar, deve revestir-se de uma série de instituições bem definidas e duplicativas que permitam ao grupo que se isola reproduzir-se dentro do perímetro estabelecido. Se os negros são o único grupo étnico a ser "hipersegregado" na sociedade norte-americana (MASSEY \& DENTON, 1992), isso ocorre porque eles são a única comunidade a combinar segregação involuntária com paralelismo organizacional, o que os prenderam dentro de um cosmos social separado e inferior, o que por sua vez acentuou o seu isolamento físico. Mas até a segregação involuntária na base da ordem urbana não produz guetos eo ipso - e isso está demons- trado no fim que levaram os banlieues franceses depois dos anos 1980. Apesar de serem extensamente deplorados como guetos pelo discurso público e de seus componentes compartilharem a percepção da exclusão em um "espaço penalizado", pleno de tédio, angústia e desespero (PÉTONNET, 1982), a relegação de seus habitantes a essas concentrações deprimidas de moradia popular na periferia urbana é baseada em classe e não em etnia. Como resultado, as concentrações são culturalmente heterogêneas, tipicamente contendo tanto famílias francesas nativas como imigrantes de dezenas de outras nacionalidades. Seus habitantes sofrem não de duplicação institucional, mas, pelo contrário, de uma falta de estrutura organizacional que seja capaz de sustentá-los na ausência de um emprego rentável e de serviços públicos adequados. Assim como as cidades britânicas e holandesas e os conglomerados de imigrantes da Alemanha urbana ou da Itália, os banlieues franceses são, sociologicamente, antiguetos (WACQUANT, 2001).

3. Guetos e bairros étnicos têm estruturas diferentes e funções opostas: se movermos a análise para além da perspectiva gradativa e focarmos o padrão peculiar das relações sociais dentro do gueto, ou entre o gueto e a cidade que o circunda, veremos uma diferença grande entre gueto e os conglomerados étnicos e bairros de imigrantes que se formaram nas metrópoles de diversos países. As "colônias" de estrangeiros da Chicago do entreguerras, que Robert Park, Ernest Burgess e Louis Wirth e, mais tarde, a tradição liberal da Sociologia e historiografia assimilacionistas confundiram com guetos brancos, eram na verdade constelações móveis e dispersas, advindas da afinidade cultural e concentração ocupacional. A segregação nessas constelações era parcial e porosa, um produto da solidariedade dos imigrantes e da atração étnica, e não imposta por um grupo hostil externo a elas. Assim, a separação residencial não era uniforme ou rígida entre esses grupos: em 1930, quando o bairro negro de Bronzeville continha $92 \%$ da população afro-americana da cidade, a "Pequena Irlanda" de Chicago continha uma mistura étnica de 25 nacionalidades compostas apenas por um terço de irlandeses e apenas 3\% da descendência irlandesa da cidade (PHILPOTT, 1978, p. 141-145).

Além disso, as instituições características dos enclaves de imigrantes europeus viravam-se para 
fora: elas operavam de maneira a facilitar a adaptação de seus habitantes ao novo meio da metrópole norte-americana. As instituições não reproduziam as organizações do país de origem e tampouco perpetuavam o isolamento social e a distinção cultural, que tipicamente desapareciam após duas gerações, conforme as pessoas aumentavam seu contato com os norte-americanos e subiam de classe social ou mudavam-se para bairros melhores (NELLI, 1970; um processo similar de difusão espacial por meio da incorporação de classe de belgas, italianos, poloneses e imigrantes ibéricos na cidade industrial francesa é analisado por NOIRIEL, 1989). Tudo isso contrasta fortemente com a exclusividade racial imutável e a alteridade institucional perene do Cinturão Negro norte-americano. Esse exemplo de Chicago demonstra o fato de o bairro de imigrantes e de o gueto terem funções diametralmente opostas: o primeiro serve de apoio para a assimilação por meio do aprendizado cultural e da mobilidade sócio-cum-espacial, enquanto o segundo é uma ilha de isolamento material e simbólico direcionada à desassimilação. O primeiro é melhor representado pela figura de uma "ponte" e o segundo por uma "parede".

\section{UMA MÁQUINA DE IDENTIDADE MACU- LADA}

O gueto não só é o meio concreto de materialização da dominação etno-racial por meio de uma segmentação espacial da cidade, como também é uma máquina de identidade coletiva potente, pois ajuda a incrustar e a elaborar justamente a divisão da qual é expressão de duas formas complementares e associadas. Primeiramente, o gueto reafirma o limite entre a categoria marginalizada e a população que a circunda, uma vez que intensifica o abismo sócio-cultural entre elas: ele faz que seus residentes sejam objetiva e subjetivamente diferentes de outros residentes urbanos ao submetê-los a condições únicas, de maneira que os padrões de cognição e conduta sejam compreendidos como singulares, exóticos ou até aberrantes (WILSON, 1987, p. 7-8; SENNETT, 1994, p. 244). Isso só serve para alimentar as crenças preconceituosas já existentes. Em segundo lugar, o gueto é um motor de combustão cultural que derrete as divisões dentro do grupo confinado e alimenta o orgulho coletivo ao mesmo tempo em que fortifica o estigma que o assola. A armadilha espacial e institucional escon- de as diferenças de classe e corrói as diferenças culturais dentro da categoria etno-racial. Assim, o ostracismo cristão fundiu os judeus asquenazes com os sefarditas sob uma identidade judia que evoluiu em um "tipo social" e em uma "forma de pensar" comum aos diversos guetos da Europa (WIRTH, 1928, p. 71-88; 1964). O gueto escuro dos EUA também acelerou a amalgamação sóciosimbólica de mulatos e negros transformando-os em uma "raça" única e também transformou a consciência racial em um fenômeno de massa, motivando a mobilização da comunidade contra a contínua exclusão de classe (DRAKE \& CAYTON, 1945, p. 390).

Ainda assim, essa identidade unificada acaba sendo marcada pela ambivalência, já que continua maculada pelo fato de a "guetização" proclamar o que Weber chama de "avaliação negativa da honra" do grupo confinado. Dessa maneira, ela promove em seus membros sentimentos de dúvida e ódio em relação a si mesmos, dissimulação de sua origem, desvalorização perniciosa de si mesmos e até a identificação fantasiosa com o dominador (CLARK, 1965, p. 63-67). Porque a "guetização" é tipicamente ligada a etnia, segregação e pobre$\mathrm{za}$, fica difícil discernir empiricamente quais das propriedades exibidas pelos habitantes do gueto são "traços culturais específicos ao gueto", em oposição às propriedades expressivas de classe, comunidade ou masculinidade (HANNERZ, 1968, p. 79). Assim também formas culturais que são fabricadas no gueto atravessam as fronteiras e circulam pela sociedade que o circunda, onde freqüentemente se transformam em sinais manifestos de rebelião cultural e excentricidade social - como se vê na fascinação de adolescentes burgueses mundo afora pelo "gangster rap" afroamericano. Isso dificulta a distinção entre formas culturais efetivamente usadas pelos residentes de guetos e a imagem pública delas que é difundida na sociedade como um todo, inclusive por meio de escritos acadêmicos.

É útil pensar o gueto e o conglomerado étnico como duas configurações ideal-típicas situadas em extremidades opostas, em um contínuo em que diferentes grupos situam-se ou pelo qual transitam, dependendo da intensidade com que as forças do estigma, do limite, do confinamento espacial e da duplicação e completude institucional coalescem-se mutuamente e impõem-se sobre eles. A "guetização" torna-se então uma variável 
de níveis múltiplos para a análise comparativa $\mathrm{e}$ especificação empírica. Ela pode ficar atenuada a ponto de, por meio da erosão gradativa de seus limites espaciais, sociais e mentais, involuir e tornar-se uma concentração étnica eletiva, operando como propulsora na integração estrutural e/ou assimilação cultural dentro da formação social geral. Isso descreve bem a trajetória das Chinatowns dos Estados Unidos do começo do século XX (ZHOU, 1994) e o status do enclave imigrante cubano em Miami, que promoveu a integração por meio do biculturalismo depois do êxodo de Mariel em 1980 (PORTES \& STEPICK, 1993). Isto também caracteriza as "Kimchee cities", para as quais os coreanos convergiram das áreas metropolitanas do Japão, e que têm uma mistura de qualidades que as tornam um híbrido de gueto e aglomeração étnica (DEVOS \& CHUNG, 1981): são lugares de infâmia que surgiram a partir da inimizade e do confinamento, mas cujas populações tornaram-se um misto étnico por meio dos anos e permitiram aos coreanos socializar e casar com seus vizinhos japoneses, assim como obter cidadania japonesa por meio da naturalização. Este esquema também se encaixa no "gueto gay", que é mais bem caracterizado como uma "comunidade quase-étnica" já que "a maior parte das pessoas gay podem 'passar' e não precisam ficar restritas à interação com os "seus" e ninguém é forçado a residir em áreas de concentração de instituições gay (MURRAY, 1979, p. 169).

A dupla face do gueto como arma e escudo implica que, na medida em que sua completude institucional e autonomia minguam, seu papel protetor para o grupo subordinado diminui, restando somente a força de sua função exclusivista. Nos casos em que residentes deixam de ter valor econômico para o grupo dominante, o encapsulamento etno-racial pode aumentar a ponto de o gueto servir como um aparato que simplesmente aloja o grupo ou prepara-o para a pior forma de ostracismo, i. e., sua destruição física. O primeiro cenário ilustra a evolução do "hipergueto" afro-americano na era pós-direitos civis: tendo perdido sua função de reservatório para o poder do emprego desqualificado, ele ligou-se de maneira simbiótica ao sistema carcerário hipertrofiado dos Estados Unidos, por meio de uma relação de homologia estrutural, substituição funcional e fusão cultural (WACQUANT, 2004). O segundo cenário foi implementado pela Alemanha nazista, que reavivou o Judenghetto entre 1939 e 1944, primeiramente para empobrecer e concentrar os judeus por meio do processo de relocação; depois, quando a deportação maciça tornou-se um incômodo, para direcioná-los aos campos de extermínio (FRIEDMAN, 1980; BROWNING, 1986).

A intensificação de sua natureza exclusivista sugere que o gueto talvez seja melhor estudado não em analogia às favelas, aos bairros de classe baixa ou aos enclaves de imigrantes, mas às reservas, aos campos de refugiados e à prisão, pertencendo assim a uma categoria maior de instituições de confinamento forçado de grupos despossuídos e desonrados. Não é por acaso que Bridewell de Londres (1555), o Zuchthaus de Amsterdam (1654) e o Hospital général de Paris (1656), cuja finalidade era ensinar a disciplina do trabalho assalariado a vagabundos, pedintes e criminosos por meio do encarceramento, foram inventados na mesma época que o gueto judeu. Também não é por acaso que o aumento de campos de refugiados em Ruanda, Sri Lanka e nos territórios ocupados da Palestina assemelham-se cada vez mais a uma mistura entre os guetos do final da Europa medieval e gulagui gigantescos.

Loïc Wacquant (loic@uclink4.berkeley.edu) é Professor de Sociologia na Universidade da Califórnia (Berkeley) e é Pesquisador do Centre de sociologie européenne do Collège de France.

\section{REFERÊNCIAS BIBLIOGRÁFICAS}

ABU-LUGHOD, J. L. 1980. Rabat : Urban Apartheid in Morocco. Princeton : Princeton University.

BROWNING, C. R. 1986. Nazi Ghettoization Policy in Poland, 1939-1941. Central European History, Leiden, n. 19, v. 4, p. 343-368, Dec.
CALdeIRA, T. 2001. City of Walls : Crime, Segregation and Citizenship in São Paulo. Berkeley, Calif. : University of California.

CLARK, K. B. 1965. Dark Ghetto : Dilemmas of Social Power. New York : Harper. 
DEVOS, G. \& DEAKYUN, C. 1981. Community Life in a Korean Ghetto. In : LEE, C. \& DEVOS, G. (eds.). Koreans in Japan : Ethnic Conflict and Accomodation. Berkeley, Calif. : University of California.

DEVOS, G. \& HIROSHI, W. (eds.). 1966. Japan's Invisible Race : Caste in Culture and Personality. Berkeley, Calif. : University of California.

ST. CLAIR, D. \& CAYTON, R. C. 1993 [1945]. Black Metropolis : A Study of Negro Life in a Northern City. Chicago : University of Chicago.

FRIEDMAN, P. 1980. The Jewish Ghettos of the Nazi Era. In : Roads to Extinction : Essays on the Holocaust. New York : The Jewish Publication Society of America.

GAY, R. 1992. The Jews of Germany: A Historical Portrait. New Haven : Yale University.

HANE, M. 1982. Peasants, Rebels, and Outcastes : The Underside of Modern Japan. New York : Pantheon.

HANNERZ, U. 1969. Soulside : Inquiries into Ghetto Culture and Community. New York : Columbia University.

HIRSCH, A. 1983. Making the Second Ghetto : Race and Housing in Chicago, 1940-1970. Cambridge : Cambridge University.

JOHNSON, J. W. 1981 [1930]. Black Manhattan. New York : Da Capo.

JOHNSON, P. 1987. Ghetto. In : . A History of the Jews. New York: Harper Perennial.

KERNER COMMISSION. 1989 [1968]. The Kerner Report. The 1968 Report of the National Advisory Commission on Civil Disorders. New York : Pantheon.

LEVINE, M. P. 1979. Gay Ghetto. Journal of Homosexuality, v. 4, n. 4, Summer.

MASSEY, D. \& DENTON, N. 1992. American Apartheid: Segregation and the Making of the Underclass. Cambridge, Mass. : Harvard University.

MINGIONE, E. (ed.). 1996. Urban Poverty and the "Underclass". Oxford : B. Blackwell.

MURRAY, S. O. 1979. The Institutional Elaboration of a Quasi-Ethnic Community. Inter- national Review of Modern Sociology, n. 9, p. 165-177, July.

NELLI, H. S. 1970. Italians in Chicago : A Study in Ethnic Mobility. New York : Oxford University.

NOIRIEL, G. 1988. Le creuset français. Paris : Seuil.

OSOFSKY, G. 1971. Harlem: The Making of a Ghetto. Negro New York, 1890-1930. $2^{\text {nd }}$ ed. New York : Harper and Row.

PERLMAN, J. 1976. The Myth of Marginality: Urban Poverty and Politics in Rio de Janeiro. Berkeley, Calif. : University of California.

PÉTONNET, C. 1982. Espaces habités. Ethnologie des banlieues. Paris : Galilée.

PHILPOTT, T. L. 1978. The Slum and the Ghetto : Neighborhood Deterioration and Middle-Class Reform, Chicago 1880-1930. New York : Oxford University.

PORTES, A. \& STEPICK, A. 1993. City on the Edge: The Transformation of Miami. Berkeley, Calif. : University of California.

QUIJANO, A. 1968. Notas sobre el concepto de marginalidad social. Santiago de Chile : Commission for Latin American Report.

SENNETT, R. 1994. Fear of Touching. In : Flesh and Stone: The Body and the City in Western Civilization. New York: W.W. Norton.

SMELSER, N. J. \& BALTES, P. B. (eds.). 2004. International Encyclopedia of the Social and Behavioral Sciences. Revised edition. London : Pergamon.

SPEAR, A. H. 1968. Black Chicago : The Making of a Negro Ghetto, 1890-1920. Chicago : University of Chicago.

STOW, K. R. 1992. Alienated Minority: The Jews of Medieval Europe. Cambridge, Mass. : Harvard University.

WACQUANT, L. 1997. A “underclass" urbana no imaginário social e científico norte-americano. Estudos Afro-asiáticos, Rio de Janeiro, n. 31, p. 37-50, out.

1998. "A Black City Within the White" : Revisiting America's Dark Ghetto. Black Renaissance, New York, v. 2, n. 1, p. 141-151. 
2001. Os condenados da cidade. Estudo sobre marginalidade avançada. Rio de Janeiro : Revan.

2004. Deadly Symbiosis : Race and the Rise of Neoliberal Penality. Cambridge, Mass. : Polity.

WARD, D. 1989. Poverty, Ethnicity, and the American City, 1840-1925. Cambridge : Cambridge University.

WESTERN, J. 1981. Outcast Cape Town. Minneapolis : University of Minnesota.
WILSON, W. J. 1987. The Truly Disadvantaged: The Inner City, the Underclass and Public Policy. Chicago : University of Chicago.

WIRTH, L. 1928. The Ghetto. Chicago : University of Chicago.

WIRTH, L. 1964 [1956]. The Ghetto. In :

On Cities and Social Life. Chicago $\overline{: \text { The }}$ University of Chicago.

ZHOU, M. 1992. Chinatown: The Socioeonomic Potential of an Urban Enclave. Philadelphia : Temple University. 